\title{
Effect of Aviation Spray Adjuvant on Improving Control of Fusarium Head Blight and Reducing Mycotoxin Contamination in Wheat
}

\author{
Xiaojing Yan (), Ming Wang, Yuxiao Zhu, Xin Shi, Xiaohui Liu, Yixuan Chen, Jun Xu, Daibin Yang \\ and Huizhu Yuan *
}

check for updates

Citation: Yan, X.; Wang, M.; Zhu, Y.; Shi, X.; Liu, X.; Chen, Y.; Xu, J.; Yang, D.; Yuan, H. Effect of Aviation Spray Adjuvant on Improving Control of Fusarium Head Blight and Reducing Mycotoxin Contamination in Wheat. Agriculture 2021, 11, 1284. https:// doi.org/10.3390/agriculture11121284

Academic Editors: Xun Zhu, Zhiguang Yuchi and Xin Yang

Received: 18 November 2021 Accepted: 14 December 2021 Published: 16 December 2021

Publisher's Note: MDPI stays neutral with regard to jurisdictional claims in published maps and institutional affiliations.

Copyright: (c) 2021 by the authors. Licensee MDPI, Basel, Switzerland. This article is an open access article distributed under the terms and conditions of the Creative Commons Attribution (CC BY) license (https:// creativecommons.org/licenses/by/ $4.0 /)$.
Institute of Plant Protection, Chinese Academy of Agricultural Sciences, Beijing 100193, China; yanxiaojing@caas.cn (X.Y.); ming.wang@nutrichem.cn (M.W.); 82101191193@caas.cn (Y.Z.); 82101185114@caas.cn (X.S.); 82101202321@caas.cn (X.L.); 82101182341@caas.cn (Y.C.); xujun@caas.cn (J.X.); yangdaibin@caas.cn (D.Y.)

* Correspondence: hzhyuan@ippcaas.cn; Tel.: +86-10-6281-5941

\begin{abstract}
Fusarium head blight (FHB) and its mycotoxin contamination are among the main factors affecting wheat yield and quality. There is an urgent need to develop an efficient strategy to prevent and control the FHB disease and reduce the mycotoxin level in the wheat product. As a triazolinthione fungicide, prothioconazole is an effective broad-spectrum fungicide to control various diseases of wheat by foliar spraying. However, prothioconazole has potential harm to the female reproductive system, and its metabolism prothioconazole-desthio has teratogenicity. Considering this point, the plant protection unmanned aerial vehicles (UAVs) are undoubtedly a suitable choice for the field application of prothioconazole. In this work, by spraying $30 \%$ prothioconazole dispersible oil suspensions, we report that aviation spray adjuvant of methylated vegetable oil influences the control effect of wheat head blight, wheat yield, prothioconazole residues, and mycotoxin deoxynivalenol (DON) content. Adding 1.0\% aviation spray adjuvant to the spray solution can significantly increase the droplet density and deposition amount in different layers of wheat canopy. The wheat yield increased by $6.94 \%$ compared with the treatment areas without spray adjuvant. Meanwhile, the prothioconazole and DON mycotoxin were not detected in the wheat grains. Based on these results, we conclude that the addition of aviation spray adjuvant can also not only ensure the high control effect of prothioconazole on FHB in wheat and increase wheat yield, but also greatly reduce the content of DON mycotoxin and ensure the safety of wheat production. This study is expected to provide theoretical guidance and data support for applying spray adjuvants in the field of plant protection UAVs in modern intensive sustainable agriculture.
\end{abstract}

Keywords: aviation spray adjuvant; UAV; prothioconazole; Fusarium head blight; mycotoxin; pesticide residue

\section{Introduction}

Wheat (Triticum aestivum L.) is one of the most important staple food crops globally [1], which greatly contributes to the food security. Fusarium head blight (FHB) is an important cereal disease that seriously threatens the safety of cereal production worldwide, resulting in reduced yields and a deterioration of grain quality because of the contamination by harmful mycotoxins [2,3]. FHB is the most important and devastative fungal disease affecting wheat cultivation [4]. In general epidemic years, it may cause a reduction in yield by $15-20 \%$, and in extreme cases, even by $60 \%$ [5]. In addition to the yield loss, Fusarium can also produce potent mycotoxins, such as deoxynivalenol (DON), which has a significant impact on the immune function of humans and animals [6]. The threshold for DON in wheat grain destined for human consumption is set at $1.00 \mathrm{mg} \mathrm{kg}^{-1} \mathrm{by}_{\text {the }}$ Chinese government [7]. Therefore, it is highly desirable to develop an efficient strategy to prevent and control the FHB disease and reduce the DON level in wheat products. 
The application strategy to control wheat head blight is spraying control in the early stage of wheat blooming. Among various sprayers, unmanned aerial vehicles (UAVs), also called drones, have aroused considerable attention in precision pest management owing to their fascinating features, mainly including flexibility, high efficiency, and lower labor intensity [8]. No specific take-off and landing sites are required; multi-rotor UAVs can operate efficiently and flexibly in complex and variable terrains and respond quickly to crop disease and insect outbreaks [9]. In recent years, the rapid innovation and development of flight control, real-time high-precision positioning, obstacle avoidance, and terrainfollowing technologies have promoted the large-scale application of UAVs in the field of crop protection [10]. Considering the characteristics of large-scale continuous planting of wheat, UAVs are especially suitable for preventing and controlling FHB in wheat.

Chemical control is still the most promising and effective method to control FHB in wheat [11]. However, to obtain increased chemical control of FHB, the fungicide selection and the timing of fungicide application would be important factors, as well as application method and rate, and good coverage of the spike [12]. Due to the increased pathogen resistance to the applied fungicides (e.g., tebuconazole, metconazole, and pyraclostrobin) and unsatisfactory application method, the control of FHB in the field has not always been consistently effective [7]. Thus, it is important to explore the effects of new fungicides and their application methods for efficient FHB management. Recently, chitosan and chitosan nanoparticles have been developed to prevent the development of FHB disease, and good control effects were achieved [13-15]. However, commercial fungicides are still the priority for the widespread field application to control FHB in wheat. As a triazolinthione fungicide with a unique chemical structure, prothioconazole, developed by Bayer Crop Science, is an effective broad-spectrum fungicide to control various wheat diseases (e.g., FHB) and other crops by foliar spraying [16]. However, prothioconazole has potential harm to the female reproductive system, and its metabolism prothioconazole-desthio has teratogenicity [17], limiting its wide registration in China due to the potential health risk for operators. Considering this point, the plant protection UAVs are undoubtedly a very suitable choice for the field application of prothioconazole.

Every coin has two sides. Although UAVs have many intriguing advantages, they still have some problems, such as pesticide loss originating from droplet drift and bouncing from the target leaves, bringing about environmental risk. The elaborate selection and application of spray adjuvants are one of the most effective methods to reduce the droplet drift and improve the deposition efficiency as well as the control effect. Wang et al. found that the type of adjuvants can significantly decrease the droplet drift by widening the droplet spectra and reducing the percentage of fine droplets [18]. Meng et al. reported that the addition of spray adjuvant could improve the efficiency of UAVs spraying by reducing the required dosage of imidacloprid by $20 \%$ [19]. Xiao et al. found that using a vegetable oil adjuvant could significantly increase the droplet coverage rate and the defoliation rate of cotton leaves [20]. However, the effects of the application of aviation spray adjuvants on pesticide residues and the content of pathogenic bacteria toxic metabolites in crops have less been exploited.

In the present study, biocompatible vegetable oil was used as an aviation spray adjuvant, and $30 \%$ prothioconazole oil-based suspension concentrate (OD) was applied as a fungicide. The effect on the droplet deposition and distribution, the control effect of FHB in wheat, and the prothioconazole residues and DON mycotoxin content in wheat samples were investigated. The present experiments were performed to verify a research hypothesis that the mycotoxin contamination in wheat could be reduced while improving the control of FHB when aviation spray adjuvant was used. This study is expected to provide theoretical guidance and data support for applying spray adjuvants in the field of plant protection UAVs in modern intensive sustainable agriculture. 


\section{Materials and Methods}

\subsection{Reagents and Materials}

Prothioconazole 30\% OD was purchased from Anhui JiuYi Agriculture Co., Ltd. (Hefei, China). Aviation spray adjuvant (methylated vegetable oil, trade name of Beidatong) was kindly provided by Mingshun Agricultural Technology Co., Ltd. (Shijiazhuang, China). With the purity of $85 \%$, Allura Red was obtained from Zhejiang Jigaode Pigment Technology Co., Ltd. (Zhejiang, China). Prothioconazole standards (98.5\%) was purchased from Dr. Ehrenstorfer $\mathrm{GmbH}$ (Augsburg, Germany). Mycotoxin standard with a purity of $98.0 \%$ was obtained from Sigma Aldrich (St. Louis, MO, USA). Chromatographic-purity acetonitrile and methanol were acquired from Fisher Scientific (Pittsburgh, PA, USA). Water was purified using a Sartorius $\mathrm{H}_{2} \mathrm{O}-\mathrm{AOV}-50$ (Sartorius Lab Instruments $\mathrm{GmbH}$ \& Co. KG, Goettingen, Germany). All other chemicals and reagents were commercially available and used as received.

\subsection{Instruments}

The type of aviation platform used was the XAG P20 aircraft (XAG Technology Co., Ltd., Guangzhou, China), which is a quadcopter with centrifugal atomization nozzles and $10 \mathrm{~kg}$ load capacity. and GNSS RTK (global navigation satellite system, real-time kinetic) high-precision navigation. The spraying system uses four spinning disc rotary atomizers, one located under each rotor. Droplet size is altered by changing the disc rpm and/or flow rate. The type of ground mechanical equipment is a tractor-mounted boom sprayer (3WPZ-1000, Zhongnong Fengmao Plant Protection Machinery Co., Ltd.,Beijing, China), which has 32 Teejet nozzles that operate at a typical pressure of $300 \mathrm{kPa}$. The spraying equipment is shown in Figure 1.
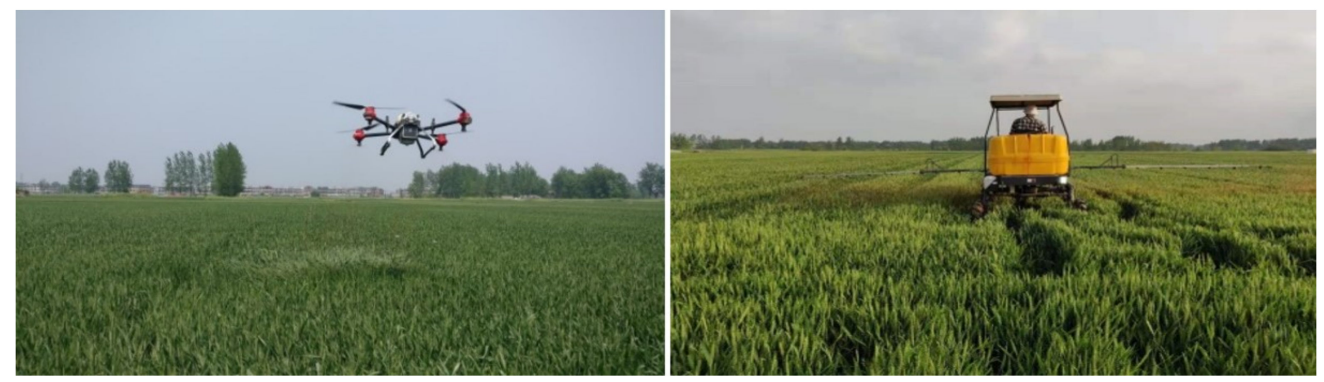

Figure 1. The UAV sprayer and tractor-mounted boom sprayer.

\subsection{Plants and Diseases}

The wheat cultivar used in this study is Huaimai 22, one of the China's most popular winter wheat cultivars, and the planting density is 678 plants $\mathrm{m}^{-2}$. Plants were grown until harvest according to local standard agronomic practices. FHB caused by F. asiaticum is the main pathogen in the local wheat plant area throughout the growing season. The pesticides were applied in the flowering period of wheat, and the critical period for FHB control when the wheat plants were approximately $80 \mathrm{~cm}$.

\subsection{Field Trials}

This field experiment was conducted on April 19, 2019, in Yingzhou District, Fuyang City, Anhui Province, China $\left(115^{\circ} 35^{\prime} 46.99^{\prime \prime}\right.$ E, $\left.32^{\circ} 54^{\prime} 50.21^{\prime \prime} \mathrm{N}\right)$, with the meteorological conditions of field temperature of $21-30{ }^{\circ} \mathrm{C}$, wind speed of $1.29-1.93 \mathrm{~m} \mathrm{~s}^{-1}$, and relative humidity of $48-62 \%$. There are four treatments in this experiment. Each treatment consisted of three replicate plots. The area of each plot for UAV application was $14 \mathrm{~m}$ (width) $\times 100 \mathrm{~m}$ (length) $=1400 \mathrm{~m}^{2}$, and the area of the tractor-mounted boom sprayer application was set as $32 \mathrm{~m}$ (width) $\times 50 \mathrm{~m}$ (length) $=1600 \mathrm{~m}^{2}$. A $10 \mathrm{~m}$ buffer zone separated each plot. The area of the blank control treatment is arranged randomly, with each plot area of $10 \mathrm{~m}$ (width) $\times 10 \mathrm{~m}$ (length). Fungicide (prothioconazole $30 \% \mathrm{OD}$ ) and avia- 
tion spray adjuvant were applied at the dosage recommended by the regulation guidelines. A blank control plot was sprayed with water. The detailed working parameters of the UAV and the tractor-mounted boom sprayer and the dosage of pesticide and adjuvant for field control against FHB were set in Table 1. The spray droplet deposition on wheat canopy and the control effects of different pesticide treatments on FBH were examined.

Table 1. The detailed working parameters and dosage of different treatments in the field experiment of control against Fusarium head blight (FHB) in wheat.

\begin{tabular}{|c|c|c|c|c|c|c|}
\hline Treatment $^{a}$ & $\begin{array}{l}\text { Spraying } \\
\text { Equipment }\end{array}$ & $\begin{array}{l}\text { Dosage }^{b} \\
\left(\mathrm{~mL} \mathrm{ha} \mathrm{h}^{-1}\right)\end{array}$ & $\begin{array}{l}\text { Adjuvant } \\
\left(\mathrm{mL} \mathrm{ha}^{-1}\right)\end{array}$ & $\begin{array}{c}\text { Water } \\
\left(\mathrm{L} \mathrm{ha}^{-1}\right)\end{array}$ & $\begin{array}{l}\text { Flight Speed } \\
\qquad\left(\mathrm{m} \mathrm{s}^{-1}\right)\end{array}$ & $\begin{array}{l}\text { Height }{ }^{d} \\
\text { (m) }\end{array}$ \\
\hline T1 & UAV & 675 & 0 & 15 & 5 & 2 \\
\hline T2 & UAV & 675 & 150 & 15 & 5 & 2 \\
\hline T3 & $\begin{array}{l}\text { Boom } \\
\text { sprayer }\end{array}$ & 675 & 0 & 300 & / & 0.5 \\
\hline $\mathrm{T} 4$ & UAV & 0 & 0 & 15 & 5 & 2 \\
\hline
\end{tabular}

$\overline{\mathrm{a}} \mathrm{T} 1$ is the abbreviation of treatment 1 , and so on. ${ }^{\mathrm{b}}$ prothioconazole $30 \% \mathrm{OD}^{\mathrm{c}}$ aviation spray adjuvant (methylated vegetable oil); ${ }^{d}$ the distance between the nozzle and the top of the wheat canopy; UAV: unmanned aerial vehicle.

The droplets collection sampling points were arranged to evaluate the deposition of spray droplets on the wheat canopy, as shown in Figure 2. Before spraying, three parallel droplet sampling belts are arranged at $10 \mathrm{~m}, 20 \mathrm{~m}$, and $30 \mathrm{~m}$ from the starting spraying position. The sampling points are perpendicular to the direction of the walking direction of the spraying equipment and are in the middle of the spraying area. There are six sampling points in each sampling belt, and the interval between the two sampling points was $0.7 \mathrm{~m}$. The sampling points were marked from left to right, the first sampling point was marked as 1 , and the last one was marked as 6 (Figure 2a). A PVC tube, a similar height with the wheat plant, was inserted at the sampling point to simulate a wheat plant. The droplets collectors, including a Kromekote ${ }^{\circledR}$ card and a filter paper, were fixed on the PVC tube with a double-ended clip to collect droplets. The upper droplets collector is fixed on the same level position with the top of the wheat canopy, the middle-level droplets collector is fixed on the middle of the PVC tube, and the lower-level droplets collector is fixed on the PVC tube $10 \mathrm{~cm}$ higher than the ground (Figure 2b).
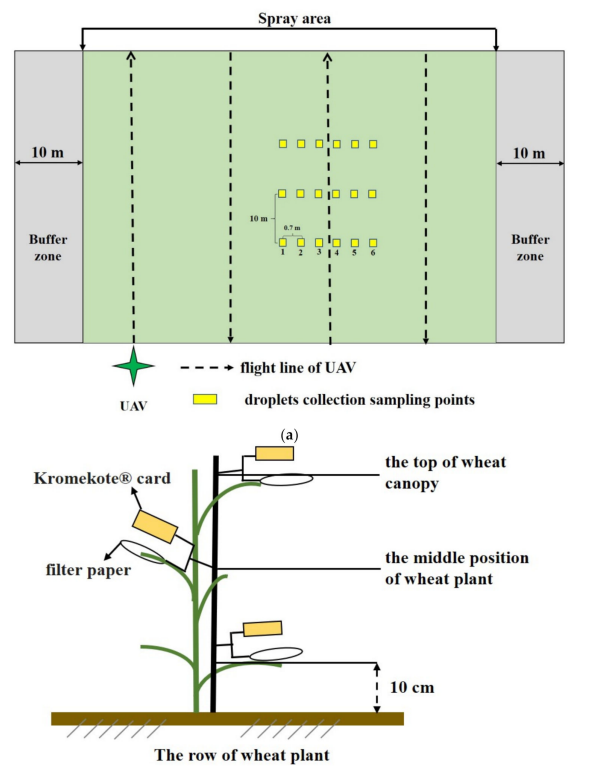

(b)

Figure 2. The droplets collection sampling points (a) and the droplets collectors (b) arrangement. 


\subsection{Determination of Droplets Deposition}

Before application, Allura Red with the concentration of $20.0 \mathrm{~g} \mathrm{~L}^{-1}$ was added into the spray solution as the tracer. Allure red, a water-soluble food dye, was frequently used as a tracer for spray deposition assessment [21]. After spraying, waiting for the droplets on the Kromekote ${ }^{\circledR}$ cards and filter papers to dye, the Kromekote ${ }^{\circledR}$ cards and filter papers on different sampling points were collected in a zip-lock bag separately and taken to the laboratory for detection. Kromekote ${ }^{\circledR}$ cards were scanned at a resolution of $600 \mathrm{dpi}$ with a scanner (Shanghai Zhongjing Technology Co., Ltd., Shanghai, China). Imagery software DropletScan (USDA, UAS) was used to analyze the droplet density and deposition [22,23].

Each filter paper placed in a separated zip-lock bag was washed with $5 \mathrm{~mL}$ of distilled water and shaken for $10 \mathrm{~min}$. Afterward, the washing solution was filtered with a syringe with a $0.45 \mu \mathrm{m}$ water-based filter membrane. The concentration of Allura Red in each extract solution was determined at $541 \mathrm{~nm}$ with a microplate reader (FlexStation 3, Molecular Devices Shanghai Ltd., Shanghai, China). The linear regression equation of the calibration curve of Allura Red was $y=0.0191 x+0.0345\left(R^{2}=0.9985\right)$.

\subsection{Control Efficacy}

The disease incidence and severity of FHB disease and the control effect (\%) against FHB were determined according to the method of Guidelines on efficacy evaluation of pesticides Part 15: Fungicides against fusarium head blight of wheat (NY/T 1464.15-2007), issued by the Institute for the Control of Agrochemicals, Ministry of Agriculture and Rural Affairs, China.

Disease incidence and severity in each plot were rated 8 days before wheat harvest using an FHB disease scale. One hundred spikes from each of five locations (four corners and the middle of the plot) were assessed for severity and incidence. FHB severity (the proportion of affected spikelets on infected spikes) was recorded visually on a scale of 0-7 representing the percentage of surfaces exhibiting visible symptoms, where $0=0 \%$ (no infection); $1=0-25 \% ; 3=25-50 \% ; 5=50-75 \% ; 7=75-100 \%$ (all spikes infected). The disease index and control efficacy for each treatment were calculated according to the Equations (1) and (2).

$$
\begin{aligned}
& D I=\frac{\sum n_{i} \times D S_{i}}{n \times D S_{\text {max }}} \times 100 \\
& C E=\frac{D I_{0}-D I_{n}}{D I_{0}} \times 100
\end{aligned}
$$

where $D I$ is the disease index, $D S_{i}$ is the different disease scale, $n_{i}$ is the total number of plants categorized in that scale, $D S_{\max }$ is the largest disease scale; $C E$ is the control efficacy, $D I_{0}$ is the disease index of no fungicide treatment control, $D I_{n}$ is the disease index of fungicide treatment.

\subsection{Wheat Yield Assessment}

Grain yields were determined 2 days before wheat harvest. There are five $1.0 \mathrm{~m} \times 1.0 \mathrm{~m}$ areas selected in each plot. Then, 20 wheat ears were grabbed randomly from the roots in each area, and the grain numbers were counted. Harvest mature wheat plants from five different locations in each plot, and dry them in a ventilated room, and then thresh and collect the plants and the grains. The thousand-grain weight of each plot is determined with 20 times repeatedly, and then the theoretical wheat yield is calculated.

A total of $1 \mathrm{~kg}$ of grain samples were taken from well-mixed wheat grains of each plot for pesticide residues and mycotoxin determinations. The wheat plants were cut into small pieces and was triturated as a powder using a household blender, and homogenized for pesticide residue analysis.

\subsection{Pesticide Residues Analysis}

To determine the residual content of prothioconazole in the wheat plant, $2.0 \mathrm{~g}$ of the homogenized plant sample (5.0 $\mathrm{g}$ for crushed wheat kernels) was weighed into a 
50-mL stoppered centrifuge tube, $5 \mathrm{~mL}$ of water and $10 \mathrm{~mL}$ of acetonitrile (containing $1 \%$ acetic acid) were added. After shaking for $30 \mathrm{~min}, 3.0 \mathrm{~g}$ of anhydrous sodium acetate was added immediately. The mixture was cooled in an ice-water bath, vortexed for $1 \mathrm{~min}$, and centrifuged at $5000 \mathrm{r} \mathrm{min}^{-1}$ for $5 \mathrm{~min}$. Then $1.5 \mathrm{~mL}$ of the supernatant was transferred to a 2-mL tube containing $50 \mathrm{mg}$ of $\mathrm{C}_{18}$ packing and $150 \mathrm{mg}$ of anhydrous magnesium sulfate, vortexed for $1 \mathrm{~min}$, and centrifuged at $5000 \mathrm{r} \mathrm{min}^{-1}$ for $5 \mathrm{~min}$. The supernatant extract was filtered through a $0.22-\mu \mathrm{m}$ polyethersulfone membrane for ultra-performance liquid chromatography-tandem quadrupole mass spectrometry (UPLC-MS/MS) analysis.

The HPLC system comprised an Acquity UPLC-TQS LC/MS/MS system (Waters Corporation, Milford, MA USA) with an Acquity UPLC BEH C 18 column $(2.1 \times 100 \mathrm{~mm}$, $1.7 \mu \mathrm{m})$. The linear gradient elution using a binary gradient composed of water containing $0.2 \%(v / v)$ formic acid (A) and acetonitrile (B) was as follows: $10-90 \%$ B (0-1.5 min); 90\% B (1.5-3.0 $\mathrm{min}) ; 90-10 \% \mathrm{~B}(3.0-3.1 \mathrm{~min})$; and 10\% B (3.1-5.0 $\mathrm{min})$. The flow rate and injected volume were set to $0.3 \mathrm{~mL} \mathrm{~min}^{-1}$ and $5 \mu \mathrm{L}$, and the column temperature was kept at $30^{\circ} \mathrm{C}$. The mass spectrometer was equipped with an electrospray ionization ion source. Prothioconazole was detected in multiple reaction monitoring (MRM) mode using negative ionization, and the $\mathrm{m} / \mathrm{z}$ values of parent and quantification ions were 342.2 and 125.0, respectively, and the collision potential was $40 \mathrm{eV}$. Prothioconazole-desthio was also detected in MRM mode but with positive ionization, and the $\mathrm{m} / \mathrm{z}$ values of parent and quantification ions were 312.2 and 70.0, respectively, and the collision potential was $36 \mathrm{eV}$. Other source parameters were as follows: capillary voltage, $3.1 \mathrm{kV}$; ion source temperature, $150{ }^{\circ} \mathrm{C}$; dry gas temperature, $200{ }^{\circ} \mathrm{C}$; drying gas flow, $80 \mathrm{~L} \mathrm{~min}^{-1}$.

\subsection{Mycotoxin Analysis}

To investigate the mycotoxin contamination in the wheat grain, each homogenized grain $(5 \mathrm{~g})$ was weighed into a $50-\mathrm{mL}$ polypropylene centrifuge tube to which $10 \mathrm{~mL}$ of acetonitrile and $1 \mathrm{~mL}$ of water were added as extraction solvent. The tubes were then homogenized for $2 \mathrm{~min}$ at $20,627 \times \mathrm{g}$ before adding $1.0 \mathrm{~g}$ of $\mathrm{NaCl}$ and $2.0 \mathrm{~g}$ of $\mathrm{MgSO}_{4}$ to separate the acetonitrile from the water. After centrifugation for $5 \mathrm{~min}$ at $4000 \times g, 2.0 \mathrm{~mL}$ of the supernatant extract was filtered through a $0.22-\mu \mathrm{m}$ polyethersulfone membrane for UPLC-MS/MS analysis.

The UPLC system comprised an Agilent 1290 Infinity/6495 LC/MS/MS system (Agilent, Quantum Analytics, Inc., Foster City, CA, USA) with an $\mathrm{XDB}^{-\mathrm{C}_{18}}$ column $(2.1 \times 100 \mathrm{~mm}, 1.7 \mu \mathrm{m})$. The mobile phase was water containing $2 \mathrm{mM}$ ammonium formate with $0.1 \%$ formic acid (phase A) and acetonitrile with $0.1 \%$ formic acid (phase B). The mycotoxins were eluted following a gradient elution program with a flow rate held at $0.2 \mathrm{~mL}$ $\min ^{-1}$ as follows: $0 \min 90 \%$ B, $1.5 \mathrm{~min} 90 \% \mathrm{~B}, 3.5 \mathrm{~min} 65 \% \mathrm{~B}, 5.5 \mathrm{~min} 25 \% \mathrm{~B}, 7.0 \mathrm{~min} 90 \% \mathrm{~B}$, and kept constant for $2 \mathrm{~min}$ for column re-equilibration; yielding a total chromatographic run of nine minutes. The sample injection volume was set at $10 \mu \mathrm{L}$. The column and autosampler were maintained at $25^{\circ} \mathrm{C}$. DON was detected in MRM mode using positive electrospray ionization. Other MS parameters were as follows: the de-solvation temperature at $300{ }^{\circ} \mathrm{C}$, source temperature at $120^{\circ} \mathrm{C}$, the capillary voltage at $3.0 \mathrm{kV}$, de-solvation gas (nitrogen) at $600 \mathrm{~L} \mathrm{~h}^{-1}$. The $\mathrm{m} / \mathrm{z}$ values of parent and quantification ions were 297.2 and 248.9 , respectively.

\subsection{Statistical Analysis}

Statistical analysis was performed using the Origin software (Origin Lab 2018, Northampton, MA, USA). One-way ANOVA was performed followed by Duncan's multiple range test to study the effect of aviation spray adjuvant on control effect against FHB in wheat and wheat yield (For Disease Index, $F=21.835, D F=3, p<0.005$; for Efficacy, $F=4.439, D F=2$, $p>0.05$; for Yield, $F=1168.782, D F=3, p<0.005$ ).

The Shapiro-Wilk test was applied to evaluate the normality of the distribution of spray droplets. $p<0.05$ was accepted as significant. 


\section{Results and Discussion}

\subsection{Effect of Aviation Spray Adjuvants on Droplet Deposition}

Spray adjuvants greatly influence on the deposition characteristics of spray droplets [24]. Xiao et al. found that adding aviation spray adjuvant vegetable oil could significantly improve the defoliant droplet deposition on cotton leaves [20]. Wang et al. [25] and He et al. [26] found that reasonable adjuvant addition helps to improve the droplet density and deposition rate during the aerial spraying. When $0.1 \%$ pinolene spray adjuvant was added into the tebuconazole solution, the droplet deposition on leaves of Photinia $\times$ fraseri Dress. and Carya cathayensis Sarg. with UAVs spraying was obviously improved [27]. Table 2, Figures 3 and 4 display the effect of aviation spray adjuvant on droplet deposition characters, including droplets density and deposition amount of pesticide. The in-swath distribution patterns of spray droplets are similar with or without adjuvant added in the spray solution through drone spraying. The relationship between the distribution of spray droplets and the sampling location in one spray swath followed a normal distribution $(\mathrm{DF}=6, p>0.05)$ (Figures 3 and 4 ).

Table 2. The effect of aviation spray adjuvant on droplet density and deposition in different layers of wheat canopy.

\begin{tabular}{|c|c|c|c|c|c|c|}
\hline \multirow[t]{2}{*}{ Wheat Canopy } & \multirow[t]{2}{*}{ Treatment $^{a}$} & \multirow[t]{2}{*}{ Sample Points } & \multicolumn{2}{|c|}{$\begin{array}{c}\text { Droplets Density } \\
{\text { (Droplets Number } \mathrm{cm}^{-2} \text { ) }}^{\text {Droplo }}\end{array}$} & \multicolumn{2}{|c|}{ Deposition $\left(\mu \mathrm{g} \mathrm{cm}^{-2}\right)$} \\
\hline & & & Mean & RSD & Mean & RSD \\
\hline \multirow{12}{*}{ Upper layer } & \multirow{6}{*}{ Pro } & 1 & $51.97 \pm 1.39$ & \multirow{6}{*}{9.91} & $1.18 \pm 0.18$ & \multirow{6}{*}{43.09} \\
\hline & & 2 & $157.70 \pm 1.55$ & & $1.47 \pm 0.20$ & \\
\hline & & 3 & $172.40 \pm 3.90$ & & $3.02 \pm 0.13$ & \\
\hline & & 4 & $142.30 \pm 3.48$ & & $1.60 \pm 0.07$ & \\
\hline & & 5 & $81.87 \pm 0.67$ & & $1.55 \pm 0.27$ & \\
\hline & & 6 & $62.07 \pm 1.59$ & & $1.05 \pm 0.07$ & \\
\hline & \multirow{6}{*}{ Pro + AD } & 1 & $77.93 \pm 3.88$ & \multirow{6}{*}{3.28} & $1.49 \pm 0.14$ & \multirow{6}{*}{30.98} \\
\hline & & 2 & $242.30 \pm 3.96$ & & $2.33 \pm 0.11$ & \\
\hline & & 3 & $184.20 \pm 4.84$ & & $2.93 \pm 0.17$ & \\
\hline & & 4 & $104.30 \pm 3.41$ & & $2.69 \pm 0.21$ & \\
\hline & & 5 & $95.50 \pm 3.73$ & & $2.48 \pm 0.45$ & \\
\hline & & 6 & $65.23 \pm 3.55$ & & $1.23 \pm 0.09$ & \\
\hline \multirow{12}{*}{ Middle layer } & \multirow{6}{*}{ Pro } & 1 & $21.27 \pm 1.42$ & \multirow{6}{*}{60.35} & $0.05 \pm 0.03$ & \multirow{6}{*}{79.34} \\
\hline & & 2 & $47.30 \pm 0.46$ & & $0.19 \pm 0.03$ & \\
\hline & & 3 & $70.70 \pm 5.84$ & & $0.65 \pm 0.02$ & \\
\hline & & 4 & $34.30 \pm 0.26$ & & $0.55 \pm 0.05$ & \\
\hline & & 5 & $24.30 \pm 2.71$ & & $0.45 \pm 0.08$ & \\
\hline & & 6 & $18.30 \pm 0.85$ & & $0.06 \pm 0.02$ & \\
\hline & \multirow{6}{*}{ Pro + AD } & 1 & $27.00 \pm 0.47$ & \multirow{6}{*}{14.41} & $0.26 \pm 0.04$ & \multirow{6}{*}{41.12} \\
\hline & & 2 & $45.80 \pm 2.87$ & & $0.51 \pm 0.05$ & \\
\hline & & 3 & $74.90 \pm 1.42$ & & $0.56 \pm 0.04$ & \\
\hline & & 4 & $36.30 \pm 5.33$ & & $0.72 \pm 0.05$ & \\
\hline & & 5 & $31.00 \pm 8.11$ & & $0.63 \pm 0.07$ & \\
\hline & & 6 & $22.10 \pm 1.15$ & & $0.22 \pm 0.07$ & \\
\hline
\end{tabular}


Table 2. Cont.

\begin{tabular}{|c|c|c|c|c|c|c|}
\hline \multirow[t]{2}{*}{ Wheat Canopy } & \multirow{2}{*}{ Treatment $^{a}$} & \multirow[t]{2}{*}{ Sample Points } & \multicolumn{2}{|c|}{$\begin{array}{c}\text { Droplets Density } \\
\text { (Droplets Number } \mathrm{cm}^{-2} \text { ) }\end{array}$} & \multicolumn{2}{|c|}{ Deposition $\left(\mu \mathrm{g} \mathrm{cm}^{-2}\right)$} \\
\hline & & & Mean & RSD & Mean & RSD \\
\hline \multirow{12}{*}{ Lower layer } & \multirow{6}{*}{ Pro } & 1 & $7.80 \pm 0.58$ & \multirow{6}{*}{46.54} & $0.03 \pm 0.01$ & \multirow{6}{*}{63.59} \\
\hline & & 2 & $15.90 \pm 2.86$ & & $0.05 \pm 0.01$ & \\
\hline & & 3 & $8.50 \pm 1.08$ & & $0.07 \pm 0.02$ & \\
\hline & & 4 & $8.10 \pm 1.00$ & & $0.11 \pm 0.02$ & \\
\hline & & 5 & $5.30 \pm 0.15$ & & $0.03 \pm 0.01$ & \\
\hline & & 6 & $3.90 \pm 0.31$ & & $0.02 \pm 0.01$ & \\
\hline & \multirow{6}{*}{ Pro + AD } & 1 & $14.80 \pm 2.66$ & \multirow{6}{*}{23.36} & $0.07 \pm 0.02$ & \multirow{6}{*}{43.86} \\
\hline & & 2 & $24.70 \pm 3.27$ & & $0.08 \pm 0.02$ & \\
\hline & & 3 & $14.40 \pm 1.04$ & & $0.16 \pm 0.03$ & \\
\hline & & 4 & $13.10 \pm 2.63$ & & $0.18 \pm 0.04$ & \\
\hline & & 5 & $8.80 \pm 0.45$ & & $0.12 \pm 0.01$ & \\
\hline & & 6 & $7.50 \pm 0.49$ & & $0.08 \pm 0.02$ & \\
\hline
\end{tabular}

a Pro: prothioconazole 30\% OD only, working parameters and dosage of fungicide applied are shown in T1 (Table 1); Pro + AD: prothioconazole $30 \%$ OD and aviation spray adjuvant (methylated vegetable oil), working parameters and dosage of fungicide and adjuvant applied are shown in T2 (Table 1).

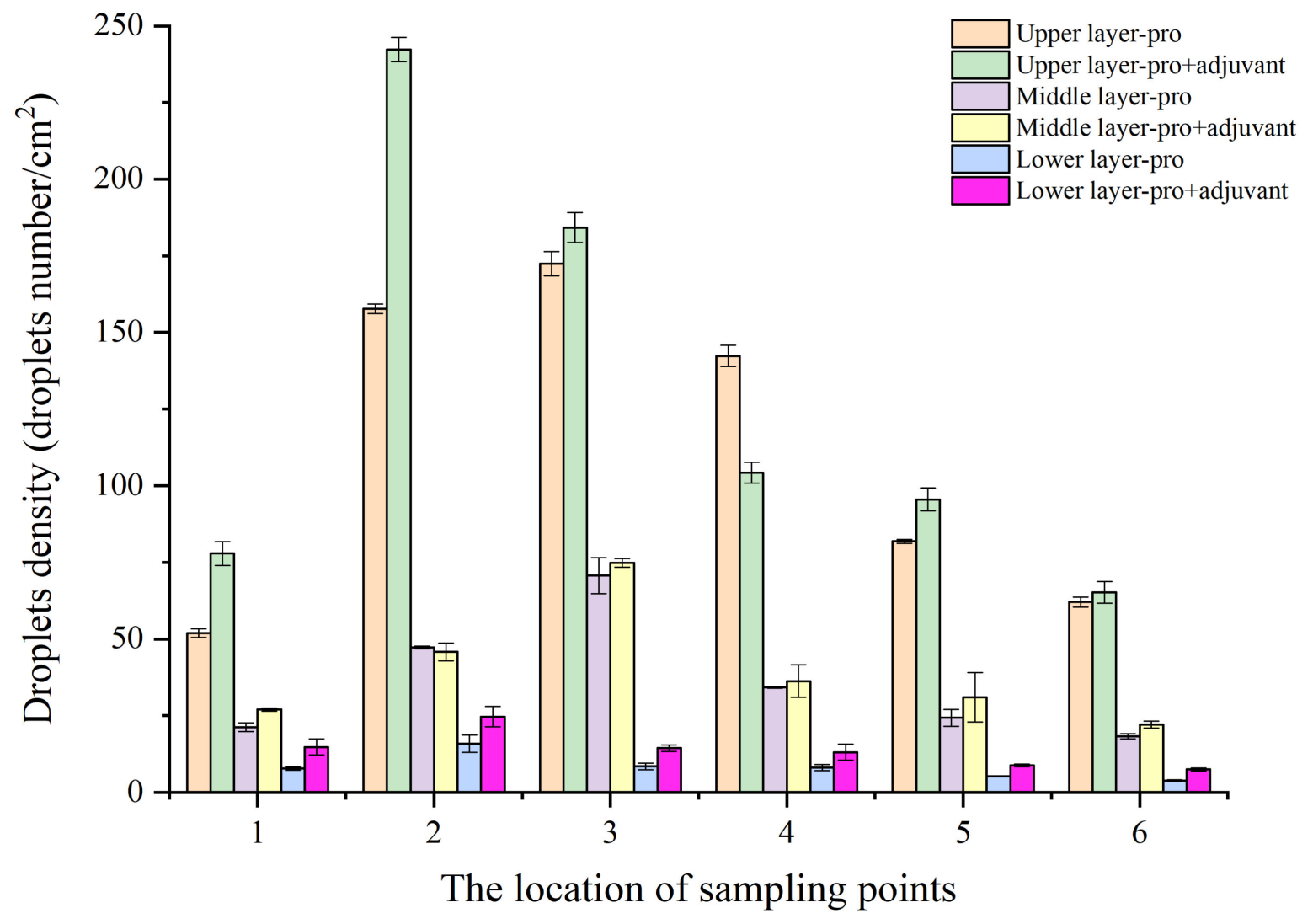

Figure 3. Effect of the aviation spray adjuvant on droplets density in the wheat canopy. 


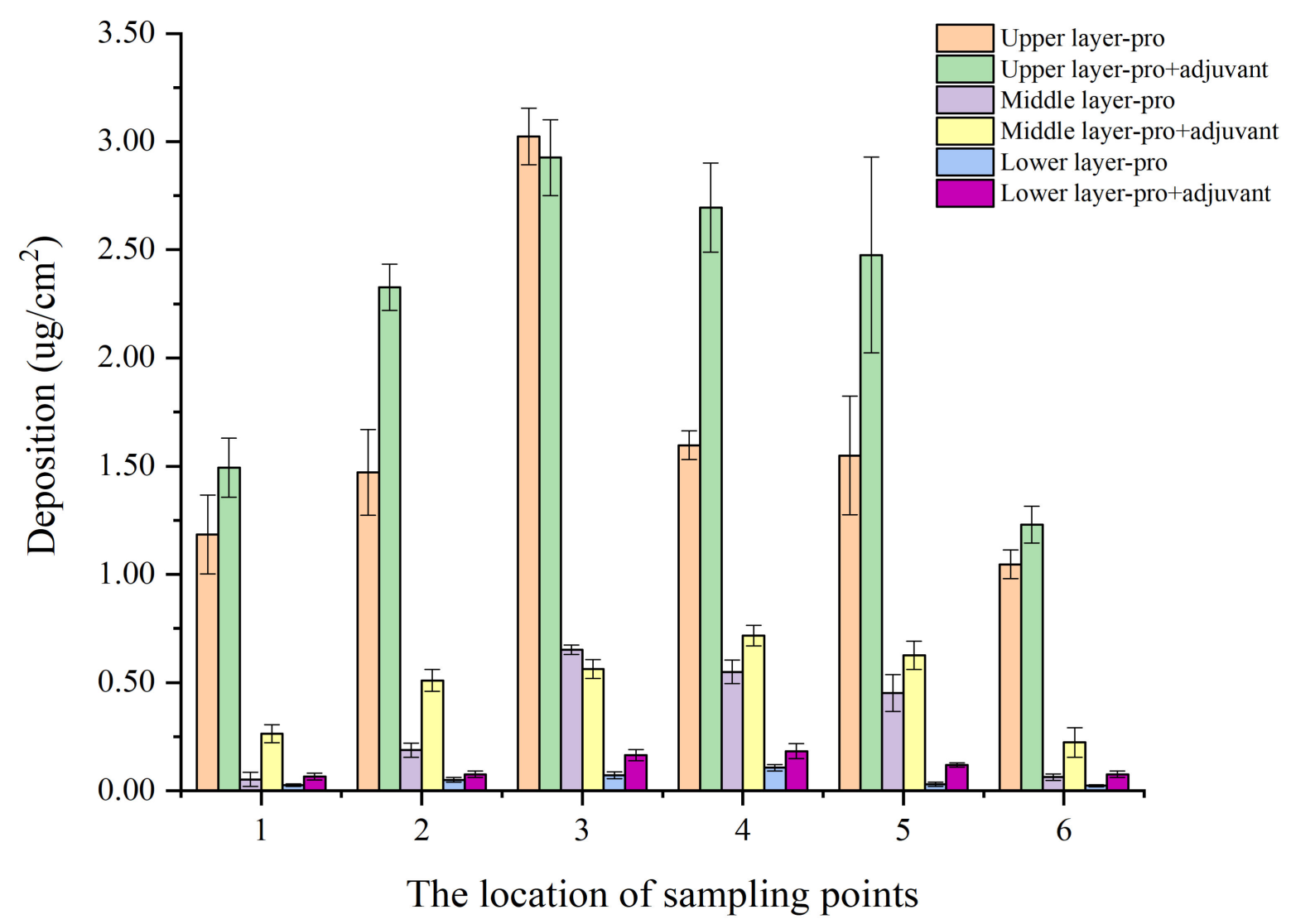

Figure 4. Effect of the aviation spray adjuvant on deposition in the wheat canopy.

The droplet density of prothioconazole $30 \%$ OD with the spray adjuvant in the wheat canopy (65.23 242.30 droplets $\mathrm{cm}^{-2}$ for the upper layer, 22.10 74.90 droplets $\mathrm{cm}^{-2}$ for the middle layer, and 7.50 24.70 droplets $\mathrm{cm}^{-2}$ for the lower layer) was significantly higher than that of no adjuvant (51.97 172.40 droplets $\mathrm{cm}^{-2}$ for the upper layer, 18.30 70.70 droplets $\mathrm{cm}^{-2}$ for the middle layer and 3.90 15.90 droplets $\mathrm{cm}^{-2}$ for the lower layer) (Table 2 and Figure 3). The deposition amount of pesticide in the wheat canopy $\left(1.23 \sim 2.93 \mu \mathrm{g} \mathrm{cm}^{-2}\right.$ for the upper layer, $0.22 \sim 0.72 \mu \mathrm{g} \mathrm{cm}^{-2}$ for the middle layer, and $0.07 \sim 0.16 \mu \mathrm{g} \mathrm{cm}^{-2}$ for the lower layer) was mostly higher than that of no adjuvant added (1.05 3.02 $\mathrm{g} \mathrm{cm}^{-2}$ for the upper layer, $0.06 \sim 0.65 \mu \mathrm{g} \mathrm{cm}^{-2}$ for the middle layer, and $0.02 \sim 0.11 \mu \mathrm{g} \mathrm{cm}^{-2}$ for the lower layer) (Table 2 and Figure 4).

The spray droplets of spray liquid are both mainly deposited in the upper layer of the wheat canopy, and the droplet density in the upper layer of the wheat canopy was also significantly higher than that of in the middle layer and lower layer of the wheat canopy, whether the aviation spray adjuvant added or not (Table 2, Figures 3 and 4). However, with the addition of spray adjuvant to the spray liquid, compared with no spray adjuvant, the proportion of droplets deposition on the upper layer of the wheat canopy in the total deposition amount is reduced from $70.9 \sim 93.8 \%$ to $75.0 \sim 82.0 \%$, the proportion of droplets deposition on the middle layer of the wheat canopy increased significantly, and, the proportion of droplets deposition on the lower layer of the wheat canopy increased slightly in-swath. Meanwhile, the RSD value of droplets density and deposition amount between different sample points were decreased with the adjuvant added (Table 2). These results suggest that the addition of aviation spray adjuvant during UAVs spraying can increase the droplet density and deposition amount in different layers of wheat canopy, increase the penetration performance of spray droplets, and improve spray uniformity in-swath. 


\subsection{Effect of Aviation Spray Adjuvants on FHB Control and Wheat Yield}

As shown in Table 3, when the dosage was $15 \mathrm{~L} \mathrm{hm}^{-2}$, the application of prothioconazole $30 \%$ OD by UAV had a good control effect of $96.64 \%$ on FHB in wheat (T1). The disease index of 1.52 was lower than that of only water applied (T4). When aviation spray adjuvant of methylated vegetable oil was added, the disease index was reduced to 0.38 and the control effect increased to $99.16 \%$ (T2), demonstrating that spray adjuvant could improve the control efficiency against disease and pests. The results were consistent with the reported findings that the addition of aviation spray adjuvants could enhance the control effect against the target to some extent. The control efficiency of wheat aphid at wheat flowering and grain filling stage was improved by adding adjuvants methylated vegetable oil and organosilicone even with reduced insecticide imidacloprid dosage [19]. It has been reported that the defoliation rate of cotton leaves increased by $3.12-34.62 \%$, and the boll opening rate increased by $6.67-29.56 \%$ after the addition of aviation spray adjuvant vegetable oil [20]. Zang et al. reported that when a hyperbranched polymer adjuvant was added in water-dispersible granules at a volume rate of $12 \mathrm{~L} \mathrm{hm}^{-2}$ sprayed with UAV, the droplet deposition on maize leaves and maize borer control was increased by $104 \%$ and $46 \%$, respectively [28]. The spraying application by boom sprayer had a comparable control effect with UAV spraying (T3).

Table 3. The effect of aviation spray adjuvant on control effect against FHB in wheat and wheat yield.

\begin{tabular}{cccc}
\hline Treatment $^{\mathbf{a}}$ & Disease Index & Control Effect (\%) & Yield (kg hm $^{-\mathbf{2}} \mathbf{)}$ \\
\hline T1 & $1.52 \pm 0.72 \mathrm{~b}$ & $96.64 \pm 1.58 \mathrm{~b}$ & $9334.1 \pm 148.8 \mathrm{c}$ \\
T2 & $0.38 \pm 0.44 \mathrm{~b}$ & $99.16 \pm 0.96 \mathrm{a}$ & $9981.6 \pm 114.9 \mathrm{a}$ \\
T3 & $0.48 \pm 0.33 \mathrm{~b}$ & $98.94 \pm 0.72 \mathrm{a}$ & $9644.4 \pm 117.7 \mathrm{~b}$ \\
T4 & $45.41 \pm 16.52 \mathrm{a}$ & $/$ & $7832.6 \pm 111.1 \mathrm{~d}$ \\
\hline
\end{tabular}

$\bar{a}$ The working parameters and dosage of fungicide and adjuvant applied of each treatment are shown in T1-T4 (Table 1). Different letters in the same column are significantly different at $p<0.05$.

In addition to improve the control efficiency with the addition of spray adjuvant, the effect on the wheat yield was also explored. As indicated in Table 3, the theoretical wheat yields under the chemical treatment with prothioconazole (T1, T2, and T3) were significantly higher than that of the blank control (T4). Indeed, control of FHB of wheat with appropriate fungicides can improve the wheat yield. Cromey et al. reported that FHB incidence was reduced by up to $90 \%$ and wheat yield increased by $14 \%$ after two applications of tebuconazole at a range of crop growth stages around flowering [29]. The addition of spray adjuvant had a significant effect on the thousand-grain weight and wheat yield but had no significant effect on the number of grains per spike. When $1.0 \%$ vegetable oil additives were added, the thousand-grain weight and theoretical yield of wheat reached the highest, which were $47.2 \mathrm{~g}$ and $9981.6 \mathrm{~kg} \mathrm{hm}^{-2}$ (T2), which were higher than the treatment without spraying additives (T1). Similarly, the spraying application by boom sprayer had a comparable wheat yield with that of UAV spraying (T3).

\subsection{Effect of Aviation Spray Adjuvants on Prothioconazole Residue and DON Content}

Prothioconazole is easily metabolized in plants and converted to prothioconazoledesthio [30]. According to the National Food Safety Standard-Maximum Residue Limits for Pesticides in Food (GB 2763-2021), the maximum residue limit (MRL) value of prothioconazole in wheat is identified with the concentration of prothioconazole-desthio, which is $0.1 \mathrm{mg} \mathrm{kg}^{-1}$. It's reported that the application method and formulation could affect the prothioconazole degradation and residue in wheat [7]. This study determined the effect of aviation spray adjuvant on the prothioconazole residue in wheat (Table 4). The residual amount of prothioconazole-desthio in wheat samples treated without spray adjuvant was $0.12 \mathrm{mg} \mathrm{kg}^{-1}$ (T1). After adding spray additives, the residual amount of prothioconazole-desthio in wheat samples was $0.13 \mathrm{mg} \mathrm{kg}^{-1}$ (T2), which was a little higher than that without adjuvant. This phenomenon is easy to understand. As described above, the addition of spray adjuvant vegetable oil could enhance the deposition of spray droplets 
on the target plant. Meng et al. also found that when organosilicone adjuvant was added for UAV spraying, the initial imidacloprid residues on wheat leaves and heads after $2 \mathrm{~h}$ were higher than those of spraying without adjuvant [19]. The prothioconazole-desthio in wheat plant samples sprayed by UAV was less than that with boom sprayer $\left(0.22 \mathrm{mg} \mathrm{kg}^{-1}\right)$ (T4). Importantly, there were no prothioconazole-desthio detected in wheat grain with or without the addition of spray adjuvant vegetable oil, indicating the food safety of wheat production with the application of prothioconazole.

Table 4. The effect of aviation spray adjuvant on residues of prothioconazole-desthio and deoxynivalenol (DON) in wheat plant and grain.

\begin{tabular}{cccc}
\hline Treatment $^{\text {a }}$ & $\begin{array}{c}\text { Prothioconazole-Desthio } \\
\text { in the Wheat Plant }\left(\mathbf{m g ~ k g}^{-\mathbf{1}}\right)\end{array}$ & $\begin{array}{c}\text { Prothioconazole-Desthio } \\
\text { in Wheat Grain }\left(\mathbf{m g ~ k g}^{-\mathbf{1}}\right)\end{array}$ & $\begin{array}{c}\text { DON in Wheat } \\
\left.\text { Grain } \mathbf{( m g ~ k g} \mathbf{~}^{-\mathbf{1}}\right)\end{array}$ \\
\hline T1 & 0.12 & ND & 0.18 \\
T2 & 0.13 & ND & ND \\
T3 & 0.22 & ND & 0.13 \\
T4 & - & - & 0.30 \\
\hline
\end{tabular}

a The working parameters and dosage of fungicide and adjuvant applied of each treatment are shown in T1-T4 (Table 1). The detection limits for prothioconazole-desthio and DON were 0.01 and $0.02 \mathrm{mg} \mathrm{kg}^{-1}$, respectively. ND: not detected.

Deoxynivalenol, also called vomitoxin, is one of the most common mycotoxins produced by Fusarium species, prevalent worldwide in crops used for food and feed production [31]. All over the world, the economic losses caused by DON through contaminating crops are in the range of billions of dollars every year [32]. DON affects animal and human health, causing acute temporary nausea, vomiting, abdominal pain, dizziness, diarrhea, headache, and fever [33]. Because of DON's toxicity, MRLs for DON in food and feed have been established to protect consumers. Due to the origin of DON from FHB, the effective control of FHB can eliminate the content of DON. As shown in Table 4, the DON in wheat grain without any treatment was $0.30 \mathrm{mg} \mathrm{kg}^{-1}$ (T4). When UAV used prothioconazole, the value was decreased to $0.18 \mathrm{mg} \mathrm{kg}^{-1}$ (T1), far below the established threshold for DON in a wheat grain of $1.00 \mathrm{mg} \mathrm{kg}^{-1}$. However, when spray adjuvant vegetable oil was applied, the DON was not detected in wheat grain (T2). The decreased tendency was consistent with the increased FHB control effect with the addition of spray adjuvant. Váňová et al. reported that the addition of Silwet L-77 adjuvant with azole fungicides could reduce the mycotoxins content in grain and malt of spring barley [34]. The present result demonstrated that the reasonable utilization of aviation spray adjuvant could provide a useful strategy to enhance the control effect against FHB and decrease the mycotoxins in wheat grain.

\section{Conclusions}

In the present study, biocompatible methylated vegetable oil was used as an aviation spray adjuvant and 30\% prothioconazole OD was applied as a fungicide to control FHB in wheat. The effect of aviation spray adjuvant on the droplet deposition and distribution, the control effect of FHB in wheat as well as the prothioconazole residues and DON mycotoxin content in wheat samples were explored, which was to verify a research hypothesis that the mycotoxin contamination in wheat could be reduced while improving the control of FHB when aviation spray adjuvant was used. Based on the investigation, the addition of aviation spray adjuvant methylated vegetable oil during UAV spraying has the following advantages: (1) increase the droplet density and deposition amount in different layers of the wheat canopy; (2) enhance the penetration performance of spray droplets; (3) ensure the high control effect of prothioconazole on FHB in wheat and increase wheat yield; (4) reduce the content of DON mycotoxin and ensure the safety of wheat production. However, this is just one case-by-case study. Further research should be conducted to confirm whether different types of aviation spray adjuvants can generally decrease the mycotoxin contamination in wheat. Even so, this study gives valuable information on disease control, and is expected to provide theoretical guidance and data support for the 
application of spray adjuvants in the field of plant protection UAVs in modern intensive sustainable agriculture.

Author Contributions: Conceptualization, X.Y. and H.Y.; methodology, X.Y. and M.W.; software, D.Y.; validation, M.W. and Y.Z.; formal analysis, X.Y. and X.L.; investigation, X.Y., M.W., Y.C. and X.S.; resources, J.X.; data curation, D.Y. and X.Y.; writing-original draft preparation, X.Y., X.S. and Y.Z.; writing —review and editing, D.Y. and H.Y.; visualization, X.L.; supervision, H.Y.; project administration, X.Y.; funding acquisition, X.Y. All authors have read and agreed to the published version of the manuscript.

Funding: This research was funded by the National Natural Science Foundation of China (NSFC) (No. 32072468). Special thanks to Prof. Wei Guo at Institute of Food Science and Technology, Chinese Academy of Agricultural Sciences who help in analyzing the mycotoxin deoxynivalenol content in wheat grain.

Institutional Review Board Statement: Not applicable.

Informed Consent Statement: Not applicable.

Data Availability Statement: Data is contained within the article.

Conflicts of Interest: The authors declare no conflict of interest.

\section{References}

1. Guttieri, M.J.; Seabourn, B.W.; Liu, C.; Baenziger, P.S.; Waters, B.M. Distribution of cadmium, iron, and zinc in millstreams of hard winter wheat (Triticum aestivum L.). J. Agri. Food Chem. 2015, 63, 10681-10688. [CrossRef] [PubMed]

2. Lemmens, M.; Krska, R.; Buerstmayr, H.; Josephs, R.; Schumacher, R.; Grausgruber, H.; Ruckenbauer, P. Fusarium head blight reaction and accumulation of deoxynivalenol, moniliformin and zearalenone in wheat grains. Cereal Res. Commun. 2003, 31, 407-411. [CrossRef]

3. Karlsson, I.; Persson, P.; Friberg, H. Fusarium head blight from a microbiome perspective. Front. Microbiol. 2021, 12, 628373. [CrossRef] [PubMed]

4. Salgado, J.D.; Wallhead, M.; Madden, L.V.; Paul, P.A. Grain harvesting strategies to minimize grain quality losses due to Fusarium head blight in wheat. Plant Dis. 2011, 95, 1448-1457. [CrossRef]

5. Rózewicz, M.; Wyzińska, M.; Grabiński, J. The most important fungal diseases of cereals—Problems and possible solutions. Agronomy 2021, 11, 714. [CrossRef]

6. Sun, J.; Wu, Y. Evaluation of dietary exposure to deoxynivalenol (DON) and its derivatives from cereals in China. Food Control 2016, 69, 90-99. [CrossRef]

7. Gao, Q.; Ma, J.; Liu, Q.; Liao, M.; Xiao, J.; Jiang, M.; Shi, Y.; Cao, H. Effect of application method and formulation on prothioconazole residue behavior and mycotoxin contamination in wheat. Sci. Total Environ. 2020, 729, 139019. [CrossRef]

8. Iost Filho, F.H.; Heldens, W.B.; Kong, Z.; de Lange, E.S. Drones: Innovative technology for use in precision pest management. J. Econo. Entomol. 2020, 113, 1-25. [CrossRef]

9. Qin, W.C.; Qiu, B.J.; Xue, X.Y.; Chen, C.; Xu, Z.F.; Zhou, Q.Q. Droplet deposition and control effect of insecticides sprayed with an unmanned aerial vehicle against plant hoppers. Crop Prot. 2016, 85, 79-88. [CrossRef]

10. Lan, Y.; Chen, S. Current status and trends of plant protection UAV and its spraying technology in China. Int. J. Precis. Agric. Aviat. 2018, 1, 1-9. [CrossRef]

11. Reis, E.M.; Zanatta, M.; Reis, A.C. Relationship between efficacy of Fusarium head blight chemical control and deoxynivalenol contamination on wheat kernels. J. Agri. Sci. 2020, 12, 227-234. [CrossRef]

12. Yoshida, M.; Nakajima, T. Chemical control of Fusarium head blight and mycotoxin contamination in barley and wheat based on mycotoxin accumulation during grain development. Mycotoxins 2012, 62, 19-67. [CrossRef]

13. Kheiri, A.; Moosawi Jorf, S.A.; Malihipour, A.; Saremi, H.; Nikkhah, M. Application of chitosan and chitosan nanoparticles for the control of Fusarium head blight of wheat (Fusarium graminearum) in vitro and greenhouse. Int. J. Biol. Macromol. 2016, 93, 1261-1272. [CrossRef] [PubMed]

14. Khan, M.R.; Doohan, F.M. Comparison of the efficacy of chitosan with that of a fluorescent pseudomonad for the control of Fusarium head blight disease of cereals and associated mycotoxin contamination of grain. Biol. Control 2009, 48, 48-54. [CrossRef]

15. Gunupuru, L.R.; Patel, J.S.; Sumarah, M.W.; Renaud, J.B.; Mantin, E.G.; Prithiviraj, B. A plant biostimulant made from the marine brown algae Ascophyllum nodosum and chitosan reduce Fusarium head blight and mycotoxin contamination in wheat. PLoS ONE 2019, 14, e0220562. [CrossRef]

16. Casida, J.E.; Durkin, K.A. Pesticide chemical research in toxicology: Lessons from nature. Chem. Res. Toxico. 2017, 30, 94-104. [CrossRef] [PubMed]

17. Xie, Y.; Jiang, H.T.; Chang, J.; Wang, Y.H.; Li, J.Z.; Wang, H.L. Gonadal disruption after single dose exposure of prothioconazole and prothioconazole-desthio in male lizards (Eremias argus). Environ. Poll. 2019, 255, 113297. [CrossRef] [PubMed] 
18. Wang, X.N.; He, X.K.; Song, J.L.; Wang, Z.C.; Wang, C.L.; Wang, S.L.; Wu, R.C.; Meng, Y.H. Drift potential of UAV with adjuvants in aerial applications. Int. J. Agric. Biol. Eng. 2018, 11, 54-58. [CrossRef]

19. Meng, Y.H.; Lan, Y.B.; Mei, G.Y.; Guo, Y.W.; Song, J.L.; Wang, Z.G. Effect of aerial spray adjuvant applying on the efficiency of small unmanned aerial vehicle for wheat aphids control. Int. J. Agric. Biol. Eng. 2018, 11, 46-53. [CrossRef]

20. Xiao, Q.; Xin, F.; Lou, Z.; Zhou, T.; Wang, G.; Han, X.; Lan, Y.; Fu, W. Effect of aviation spray adjuvants on defoliant droplet deposition and cotton defoliation efficacy sprayed by unmanned aerial vehicles. Agronomy 2019, 9, 217. [CrossRef]

21. Gao, S.; Wang, G.; Zhou, Y.; Wang, M.; Yang, D.; Yuan, H.; Yan, X. Water-soluble food dye of Allura Red as a tracer to determine the spray deposition of pesticide on target crops. Pest Manag. Sci. 2019, 75, 2592-2597. [CrossRef]

22. Zhu, H.; Salyani, M.; Fox, R.D. A portable scanning system for evaluation of spray deposit distribution. Comput. Electron. Agric. 2011, 76, 38-43. [CrossRef]

23. Hoffmann, W.C.; Hewitt, A.J. Comparison of three imaging systems for water-sensitive papers. Appl. Eng. Agric. 2005, 21, 961-964. [CrossRef]

24. Klein, R.N.; Golus, J.A.; Nelms, K.L. The effect of adjuvants, pesticide formulation, and spray nozzle tips on spray droplet size. J. ASTM Int. 2009, 6, 1-7. [CrossRef]

25. Wang, L.J.; Liu, W.L.; Pan, Z.P.; Li, C.Y.; Zhang, Y.P.; Zhu, T.S.; Huang, S.H.; Liao, Y.L. The influence of adjuvants on the characteristics of aerial spraying about the emanectin benzoate ME and the control efficacy of the thrips. J. Environ. Entomol. 2017, 39, 940-944.

26. He, L.; Wang, G.B.; Hu, T.; Meng, Y.H.; Yan, X.J.; Yuan, H.Z. Influences of spray adjuvants and spray volume on the droplet deposition distribution with unmanned aerial vehicle (UAV) spraying on rice. J. Plant Prot. 2017, 44, 1046-1052.

27. Han, Q.Q.; Zhu, C.; Pan, J.L.; Chen, A.L. Preparation and application performance of pinolene spray adjuvant. Chin. J. Pest. Sci. 2021, 23, 176-182.

28. Zang, Y.; Zhou, Z.; Zang, Y.; Luo, X.; Liao, J.; Ming, R.; Song, C.; Zi, L.; Jiang, R.; Xiao, H. Optimization of aviation adjuvants based on wettability analysis for insecticide application on maize using UAV. Int. J. Agric. Biol. Eng. 2021, 14, 11-18. [CrossRef]

29. Cromey, M.G.; Lauren, D.R.; Parkes, R.A.; Sinclair, K.I.; Shorter, S.C.; Wallace, A.R. Control of Fusarium head blight of wheat with fungicides. Australas. Plant Path. 2001, 30, 301-308. [CrossRef]

30. Xu, C.; Cao, L.; Bilal, M.; Cao, C.; Zhao, P.; Zhang, H.; Huang, Q. Multifunctional manganese-based carboxymethyl chitosan hydrogels for $\mathrm{pH}$-triggered pesticide release and enhanced fungicidal activity. Carbohyd. Polym. 2021, 262, 117933. [CrossRef]

31. Rotter, B.A.; Prelusky, D.B.; Pestka, J.J. Toxicology of deoxynivalenol (vomitoxin). J. Toxicol. Env. Health 1996, 48, 1-34. [CrossRef] [PubMed]

32. Neme, K.; Mohammed, A. Mycotoxin occurrence in grains and the role of postharvest management as a mitigation strategies. A review. Food Control 2017, 78, 412-425. [CrossRef]

33. Sobrova, P.; Adam, V.; Vasatkova, A.; Beklova, M.; Zeman, L.; Kizek, R. Deoxynivalenol and its toxicity. Interdisc. Toxicol. 2010, 3, 94-99. [CrossRef] [PubMed]

34. Váňová, M.; Hajšlová, J.; Havlová, P.; Matušinsky, P.; Lancová, K.; Spitzerová, D. Effect of spring barley protection on the production of Fusarium spp. mycotoxins in grain and malt using fungicides in field trials. Plant Soil Environ. 2004, 50, 447-455. [CrossRef] 